\title{
Correlation between Initial Content of Starch of the Mash of Cassava (Manihot esculenta L) in Fermentation and Temperature of Distillation of Alcoholic Fermented Wort in the Course of the Production of Bioethanol in Congo
}

\author{
Diakabana Philippe $^{1-4 *}$, Simon Charles Kobawila ${ }^{3}$ and Delphin Louembé ${ }^{3}$ \\ ${ }^{1}$ Institut Supérieur de Technologie Agroalimentaire et d'Agronomie, \\ Université Libre du Congo, Brazzaville \\ ${ }^{2}$ Ecole Supérieur de Technologie des Cataractes, Brazzaville, \\ ${ }^{3}$ EPRAN-Congo, Pôle d'Excellence en Alimentation et Nutrition, Faculté des Sciences et \\ Techniques, Université Marien NGOUABI, Brazzaville \\ ${ }^{4}$ Ecole Nationale Supérieure d'Agronomie et de Foresterie, Université Marien \\ NGOUABI, Brazzaville \\ *Corresponding author
}

\section{A B S T R A C T}

Keywords

Ethanol fermentation, density of cassava mash, corn malt, ratio $\alpha$ - amylase/starch, distillation of fermented wort, concentrating of alcohol solution.

\section{Article Info}

Accepted:

28 September 2016

Available Online:

10 October 2016
This study is a contribution at the conversion of the home scale traditional activity of production of cassava brandy in industrial process of production of bioethanol in Congo. The experimental results show the possibility to control the fermentation of cassava mash by the measure of the density in keeping with starch content. The evolution of the fermentation process of cassava mash depends of the addition of maize malt, source of $\alpha$-amylase. The number of stages of temperature of distillation process increases when the density of the cassava mash submited to the ethylic fermentation is high. For a cycle of distillation of fermented wort, the temperature of extraction of ethanol is as much down as the initial density of mash on fermentating is higher. The fractions of volume of the distillate proceeding from dense worts are more alcoholic in comparison with those of worts more light. For the mash at $285 \mathrm{~g} / \mathrm{L}$ of starch, six fractions of volume of the distillate having an alcohometric title superior at $20^{\circ} \mathrm{GL}$ are collected in comparison with two fractions for the mash at $71 \mathrm{~g} / \mathrm{L}$. The redistillation process of the fractions of volume of the distillate has permitted to concentrate the alcohol content.

\section{Introduction}

The bioethanol is the ethanol of biological and agricultural origin and belonging at the family of the renewable energies. This alcohol obtained by fermentation process of worts is separated and concentrated by distillation process, then dehydrated for obtaining an anhydre product.
The world production of bioethanol is in augmentation and opens, at the present moment, the way at many opportunities (World Bank, 1980; Launder, 2001). In Congo, the brandy of cassava is traditionally produced by artisanal methods on a 
household scale (Holzapel, 1997; Diakabana Kiyindou, 2008).

In the frame of this study, ethanol is producted fondamentally from flour of cassava (Manihot esculenta L), coarsely ground of malt of maize (Zea mays L) (Tiisekwa et al., 2000; Johannes et al., 2008; Muyanja et al., 2010) and water. These traditional methods of fermentation and distillation, employing equipments very rudimentary are well mastered by the experimented producers, particularly the old persons, who have done it a money-making activity in spite of the great irregulrity of the quality of product obtained (Diakabana, 2006). Various types of alcoholic beverages of cassava are equally producted in other countries (Rakotosaona et al., 20015). The process of controled fermentation is carried out by yeasting in adding a yeast stamp Saccharomyces cereviae (Diakabana et al., 2007; Nwaga et al., 2009) at the mash of cassava (Gosselin et al., 2000).

The bilological transformation of starch into ethanol makes intervene amylases activity and ethylic fermentation to realize the saccharification-fermentation process (Diakabana et al., 2007, 2008; Stewart et al., 2008). The yeasting improves the ethanol global productivity (Diakabana et al., 2014b) and diminishes the formation of volatile acidity (Diakabana et al., 2007).

In Congo, the flour of cassava employed in preparation of this brandy originates mainly from rebus of mills of foufou (flour of retted and dried cassava roots) (Diakabana, 2006). Other-wise, in view to valorisate the endogen ancient technologies executed at the household scale (Van Noort and Spence, 1976; Moreau, 1985; Aidoo, 1994; Holzapel, 1997), the traditional method to elaborate the brandy of cassava is possible to be converted into industrial process of production of bioethanol purified, concentrated and anhydre ethanol usable at the over ways: medical and chemical domain, hard-ware, cooling down in bioindustries.

In the aim to convert the homescale traditional method of preparation of the brandy of cassava in an industrial process of production of bioethanol in Congo, the correlation between initial content of starch of the mash of cassava in fermentation process and temperature of distillation process of the fermented wort is studied.

\section{Materials and Methods}

\section{Methods of production of bioethanol}

\section{Fermentation}

\section{Conduct of the directed fermentation process of cassava mash}

Six essays of ethylic fermentation variable in terms of the content of starch $(\mathrm{E} 1=71 \mathrm{~g} / \mathrm{L}$, E2 $=89 \mathrm{~g} . \mathrm{L}, \quad \mathrm{E} 3=142 \mathrm{~g} / \mathrm{L} ， \mathrm{E} 4=178 \mathrm{~g} / \mathrm{L} ， \mathrm{E} 5=$ $249 \mathrm{~g} / \mathrm{L}$ et $\mathrm{E} 6=285 \mathrm{~g} / \mathrm{L}$ ) were tested each four times.

In view to obtain fermented wort, the coarsely ground of corn malt and the yeast were added at the porridge of cassava dough cooked (Diakabana et al., 2014b). For the planting of the samples of cassava mash at low and high densities, the following contents of dry yeast Saccharomyces cerevisiae were employed (Chlup et al., 2007) after activation (Diakabana et al., 2013a): for E1 1g/L, E2 1.5g/L, E3 2g/L, E4 $2.5 \mathrm{~g} / \mathrm{L}, \quad$ E5 $3.5 \mathrm{~g} / \mathrm{L}$ and E6 $4 \mathrm{~g} / \mathrm{L}$. After mixing, the mixture of the ingredients obtained was introduced into micro tank (Diakabana, 2008a) and the volum standardized with cool water added in sufficient quantity to make 4 liters. The 
cassava mash obtained, at $25-26^{\circ} \mathrm{C}$, was incubated for the development of the saccharification and fermentation process during four at eight days (Figure 1).

\section{Distillation}

\section{Conduct of distillation process of alcoholic fermented wort}

At the end of the fermentation process, the alcoholic fermented wort obtained was weakly diluted with one litre of water, blended, sifted and filtered then introduced in the boiler of the system of distillation without column and operating in discontinuous (Diakabana, 2008b). In the course of the operation of distillation, the alcoholic fermented wort was weakly heated by means of electric plate as far as boil and the temperature regularly measured. The steams were gradually condensed and the appearance of the distillate going out of the tube of condensation controlled. The liquid appearing before $78.5^{\circ} \mathrm{C}$ was not gotten back (Diakabana, 2006). The useful distillate appearing from $78.5^{\circ} \mathrm{C}$ was reaped by fractions of volume in a graduated cylinder, collected in a graduated phial and the alcohometric title measured (Figure 2). Several plages of temperature relative at the spraying-condesation process of the components of fermented wort were picked out and characterized.

For every cycle of distillation of alcoholic fermented wort, the collection of the distillate was carried out by fractions of volume as follows: first fraction F1 $115 \mathrm{ml}$, second fraction F2 $135 \mathrm{ml}$, third fraction F3 $150 \mathrm{ml}$, fourth fraction $\mathrm{F} 4170 \mathrm{ml}$, fifth fraction F5 $235 \mathrm{ml}$ and sixth fraction F6 240 $\mathrm{ml}$. The duration of a cycle of distillation was appreciated between the time of running of the distillate obtained from $78.5^{\circ} \mathrm{C}$ (beginning of collection of the first fraction F1) and the end of last fraction immediately evaluated at $18^{\circ} \mathrm{GL} \pm 3^{\circ} \mathrm{GL}$.
Concentrating of alcohol content of the fractions of volume of the distillate

For carry out the purity and concentrating of the alcohol, every fraction of volume of the distillate was submitted at a re distillation (bi or tridistillation) process in exchange for use of an equipment of laboratory provided with column of Vigreux, condenser, balloon in glass of $500 \mathrm{ml}$ and a heating system permitting to regularize the temperature. The redistillation process was carried out following a plage of temperature going from $78.5^{\circ} \mathrm{C}$ at $92^{\circ} \mathrm{C}$.

\section{Methods of physico-chemical analysis}

\section{Evaluation of starch content of the mash of cassava}

The evaluation of starch content of the mash was effected by the anthrone (modified) method of Haas and Fleischmann (Diakabana, 2006). The knowledge of the content of starch $(\mathrm{g} / \mathrm{L})$ permits to distinguish quantitatively the samples of the cassava mash destined at the different essays of ethylic fermentation in comparison with the march of the distillation process of ethanol.

\section{Determination of $\alpha$-amylase activity of the corn malt}

In order to appreciate the ratio $\alpha$ amylase/starch (U/g) in the mash, the enzymatic activity of $\alpha$-amylase of malt of maize used was determined according to method (modified) of iodine titration at 690nm (Diakabana, 2006).

\section{Evaluation of saccharification}

A diluted iodine test was performed on the fractions aliquot of the wort of cassava to appreciate the level of fermentation process by using the EBC method adapted by Diakabana et al., (2008). 


\section{Measurement of the density of mash of cassava into fermentation}

The density of the wort of cassava was determined at $20^{\circ} \mathrm{C}$ every day during the essays of the fermentation process by means of decimeters which the scale fluctuates between $0.900 \mathrm{~g} / \mathrm{ml}$ and $1.130 \mathrm{~g} / \mathrm{ml}$ (Diakabana et al., 2007).

\section{Determination of the temperature value}

The temperature of the wort in the tank was measured every day during the fermentation essays by means of a thermometer at plunging. During the march of distillation the temperature of the steam at the entry of the condenser was regularly measured about every minute or four minutes.

\section{Determination of alcohometric title of fractions of volume of the distillate by alcohometry}

For every cycle of distillation, the alcohometric title of the different samples of fractions of volume of the distillate collected were regularly determined at $20^{\circ} \mathrm{C}$ by means of a Gay-Lussac alcohometer which the scale goes from 0 at $100^{\circ} \mathrm{GL}$ (Diakabana, 2006).

\section{Statistical analysis of results}

For the purpose of the characterization of the production process of bioethanol of cassava-based, the method based on the law of Gauss-Lussac in bell was used as presented it Larrieu (1988), Nicolas et al. (1988) with modification, in view to appreciate the repeativity of the analysis and operations. In the course of ethylic fermentation of the cassava wort, the initial content of starch represents the means of the essays repeated four times for a coefficient of variation less than or equal at $0.1 \%$. The mean values of density of wort in terms of pouring of corn malt following the ratio $\alpha$ amylase/starch was evaluated from essays effected three times with a coefficient of variation lower at $1 \%$. The data of alcohometric title of the fractions of volume of the distillate in terms of the pouring out of the corn malt following the ratio $\alpha$ amylase/starch represent the mean of essays $\alpha$-amylase/starch in triple with a coefficient of variation lower at $5 \%$. The mean values of temperature of the distillation of the fermented worts originating from fermentation process with different initial contents of starch were obtained from essays repeated four times for a coefficient of variation lower at $5 \%$.

\section{Results and Discussion}

\section{Behaviour of the ethylic fermentation process in terms of the pouring of corn malt}

The diminution of the density in terms of time follows an hyperbolic curve. After 72 hours, the evolution of the density values in course of the fermentation are same and presents the same pace for the ratios 123.71/1, 247.13/1 and 346.36/1 (Figure 3) ; the content of starch tested was $105.5 \mathrm{~g} / \mathrm{L}$. The reach of the limit values of the density marks the end of the ethylic fermentation process (for R1 $1.01 \mathrm{~g} / \mathrm{ml}$ and R5 0.9975 $\mathrm{g} / \mathrm{ml}$ at 72 hours).

The saccharification was unfinished in the case of the fermented wort with the ratios $\square$ amylase/starch equal or lower at 61.85/1 $(\mathrm{U} / \mathrm{g})$. On the contrary it was complete with the superior ratios. Indeed, the test at iodine on the wort in end of fermentation was positive for the ratio $15.45 / 1$, lightly positive for the ratio $61,85 / 1$ and negative for the ratios equal or superior at 123.7/1. 
Other-wise, with the ratios equal or superior at $61.85 / 1$, the profile of evolution of alcohometric title of fractions of volume of the distillate has revealed a same pace (Figure 4).

\section{Evolution of the density in the course of the fermentation}

In the course of the development of the fermentation, the density of the wort relative at the content of starch has diminished progressively as far as a limit which marks the end of the process (Table 1).

The initial density of cassava mash was only determined for the samples E1 and E2 having a content of starch lower or equal at $89 \mathrm{~g} / \mathrm{L}$. For the values of initial content of starch equal or superior at $142 \mathrm{~g} / \mathrm{L}$ the wort is thick and the density non-determined. The value of the initial density of wort is more low for the weak content of starch $(1.0344 \mathrm{~g} / \mathrm{ml}$ for $\mathrm{E} 1=71 \mathrm{~g} / \mathrm{L}$ of starch and $1.0345 \mathrm{~g} / \mathrm{ml}$ for $\mathrm{E} 2=89 \mathrm{~g} / \mathrm{L}$ ).

In the course of the fermentation, the density decreases as far as a lower limit marking the end of the process, which limit density is more elevated when the initial content of starch of the mash is great $(1.010 \mathrm{~g} / \mathrm{mL}$ for E6=285 g/L of starch in comparison with $0.998 \mathrm{~g} / \mathrm{mL}$ for $\mathrm{E} 1=71 \mathrm{~g} / \mathrm{L})$. The duration of the process is more long for the case of the initial content of starch of the mash elevated.

In the course of the fermentation process, there is progressively significant fluidization of the wort and the density was determined from 96 hours for E3 (142 g/L of starch) and E4 (178 g/L), 168 hours for E5 (249 g/L) and E6 (285 g/L). The iodine test was negative for the worts more light E1-E4 and positive for the worts many more dense E5 and E6.
Evolution of the temperature of distillation of ethanol in keeping with the initial content of starch of the worts employed

For every sample of initial content of starch of the wort tested, the level of temperature in keeping with the collecting of the fractions of volume of distillate has augmented from the first fraction $\mathrm{F} 1$ to the last (Figure 5). This level of temperature value of distillation was as much as more low than the wort more dense.

With the fermented wort orginating from the mash at initial content of starch of $285 \mathrm{~g} / \mathrm{L}$, the first value of temperature of reaping of fractions of volume of the distillate is situated at on average $82.5^{\circ} \mathrm{C}$ in comparison with $93.5^{\circ} \mathrm{C}$ in the case of the mash at $71 \mathrm{~g} / \mathrm{L}$ of starch. In the course of the cycle of distillation process, every alcohometric title of a fraction of volume of the distillate corresponds with a range of the temperature more or less extensive. That has allowed at the operator to regulate manually the heating in the course of the distillation process of the fermented wort.

Evolution of alcohometric titles of the different fractions of volume of the distillate reaped in the course of a cycle of distillation

The alcoométric titles $\left({ }^{\circ} \mathrm{GL}\right)$ of the différent fractions of volume of the distillate progress in the course of distillation process of alcoholic fermented worts.

For every cycle of distillation tested, the fractions of volume of the distillate reaped have alcohometric titles decreasing (Figures 6). At every plage of values of alcohometric title corresponds a fraction of volume of the distillate of one cycle given of distillation. 
For the distillation process of sample of the fermented wort originating of fermentation of mash at $285 \mathrm{~g} / \mathrm{L}$ of starch, the first fraction $\mathrm{F} 1$ measures $65^{\circ} \mathrm{GL}$, the fourth $\mathrm{F} 4$ $40^{\circ} \mathrm{GL}$, the sixth and last fraction F6 $21^{\circ} \mathrm{GL}$. While for the sample of mash at $249 \mathrm{~g} / \mathrm{L}$ of starch, the first fraction $\mathrm{F} 1$ measures $58^{\circ} \mathrm{GL}$, the fourth $\mathrm{F} 430^{\circ} \mathrm{GL}$, the fifth and last fraction $\mathrm{F} 515^{\circ} \mathrm{GL}$.

\section{Concentrating of alcohol content of the fractions of volume of the distillate}

Every fraction of volume of distillate relative at a cycle of steaming-condensation process is submitted at the redistillation (bi or tridistillation) process. In this context of redistillation, samples of fraction of volume of the distillate of alcohol (Photo1) are concentrated by giving products of alcohometric titles varying between $70^{\circ} \mathrm{GL}$ and $93^{\circ} \mathrm{GL}$ (Photo 2).

In the formulation of the cassava mash, the pouring of various ingredients plays an important rôle in the efficiency of the ethylic fermentation (Louembé et al., 2004). The control of the quantity of maize malt, source of amylases (Nwaga et al., 2009; ZannouTchoko et al., 2011; Diakabana et al., 2013, 2014a ; Rakotosaona et al., 2015), added in the mash of cassava is important for the well march of the ethylic fermentation process (Barcelos et al., 2011).

The fermentation process is more effective with a content of starch more important (Nwaga et al., 2009). However, the more great content of starch tested $(285 \mathrm{~g} / \mathrm{L})$ is not still saturating for the ethylic fermentation. When the content of the starch increases, the speed of the fermentation decreases and the duration increases. The yeasting of porridge by a commercial pur stump Saccharomyces cerevisiae for a directed ethylic fermentation permits to avoid the intoxications by the methanol (Nwaga et al, 2009).

The number of fractions of volume of the distillate reaped having an alcohometric title superior or equal at $20^{\circ} \mathrm{GL}$ is more great for a more great density ( $\operatorname{six}$ fractions for a mash at $285 \mathrm{~g} / \mathrm{L}$ of starch in comparison with two fractions of volume of the distillate for a mash at $71 \mathrm{~g} / \mathrm{L}$ of starch).

In addition, the first fraction of the distillate obtained by distillation process of dense wort presents an alcohometric title more high $\left(65^{\circ} \mathrm{GL}\right.$ for the first fraction originating of the mash at $285 \mathrm{~g} / \mathrm{L}$ of starch in comparison with $35^{\circ} \mathrm{GL}$ in the case of the mash at $71 \mathrm{~g} / \mathrm{L}$ of starch).

In effect, the development of the fermentation process of cassava wort can be controlled by measuring regularly the density expressed in gram/litre for values of initial contents of starch lower or equal at $105.5 \mathrm{~g} / \mathrm{L}$. Beyond of this concentration, the wort becomes more and more thick and the determination of the density according to our methodology does not march. In comparison with that, the evolution of the fermentation of dense cassava wort can be followed by measuring the Brix density (Diakabana et al., 2013b). All in assuring the acceleration of the speed of the ethylic fermentation process, the augmentation of the global productivity of ethanol (Diakabana et al., 2014c) and the diminution of formation of volatil acidity, the addition of Saccharomyces cerevisiae into the mash of cassava permits to avoid the intoxications provoked by the methanol in the wort fermented (Rubio-Arroyo et al., 2011). 
Table.1 Evolution of the density of the cassava mash in terms of the content of starch. Conditions : Temperature of fermentation : $26^{\circ} \mathrm{C}$ à $28^{\circ} \mathrm{C}$.

\begin{tabular}{|c|c|c|c|c|c|c|}
\hline \multirow{2}{*}{$\begin{array}{l}\text { Duration of the } \\
\text { fermentation } \\
\text { (hour) }\end{array}$} & \multicolumn{6}{|c|}{ Content of starch relative at the formulation of the samples (E1-E6) of cassava mash tested } \\
\cline { 2 - 7 } & $\mathrm{E} 1(71 \mathrm{~g} / \mathrm{L})$ & $\mathrm{E} 2(89 \mathrm{~g} / \mathrm{L})$ & $\mathrm{E} 3(142 \mathrm{~g} / \mathrm{L})$ & $\mathrm{E} 4(178 \mathrm{~g} / \mathrm{L})$ & $\mathrm{E} 5(249 \mathrm{~g} / \mathrm{L})$ & $\mathrm{E} 6(285 \mathrm{~g} / \mathrm{L})$ \\
\cline { 2 - 7 } & $\mathrm{d}_{20}(\mathrm{~g} / \mathrm{ml})$ & $\mathrm{d}_{20}(\mathrm{~g} / \mathrm{ml})$ & $\mathrm{d}_{20}(\mathrm{~g} / \mathrm{ml})$ & $d_{20}(\mathrm{~g} / \mathrm{ml})$ & $\mathrm{d}_{20}(\mathrm{~g} / \mathrm{ml})$ & $\mathrm{d}_{20}(\mathrm{~g} / \mathrm{ml})$ \\
\hline 0 & 1,0345 & 1,0345 & $\mathrm{ND}$ & $\mathrm{ND}$ & $\mathrm{ND}$ & $\mathrm{ND}$ \\
\hline 24 & 1,014 & 1,018 & $\mathrm{ND}$ & $\mathrm{ND}$ & $\mathrm{ND}$ & $\mathrm{ND}$ \\
\hline 48 & 1,006 & 1,007 & $\mathrm{ND}$ & $\mathrm{ND}$ & $\mathrm{ND}$ & $\mathrm{ND}$ \\
\hline 72 & 1,002 & 1,001 & $\mathrm{ND}$ & $\mathrm{ND}$ & $\mathrm{ND}$ & $\mathrm{ND}$ \\
\hline 96 & 0,998 & 1,000 & 1,007 & 1,009 & $\mathrm{ND}$ & $\mathrm{ND}$ \\
\hline 120 & 0,998 & 1,000 & 1,003 & 1,004 & $\mathrm{ND}$ & $\mathrm{ND}$ \\
\hline 144 & & - & 1,000 & 1,000 & $\mathrm{ND}$ & $\mathrm{ND}$ \\
\hline 168 & - & - & 1,000 & 1,000 & 1,009 & 1,010 \\
\hline 192 & - & - & - & - & 1,008 & 1,010 \\
\hline
\end{tabular}

$\mathrm{d} 20$ : density of the mash in $\mathrm{g} / \mathrm{ml} ; \mathrm{ND}:$ non determined because mash thick

Fig.1 Diagram of ethylic fermentation directed by yeasting in cylindrical-conical micro tank

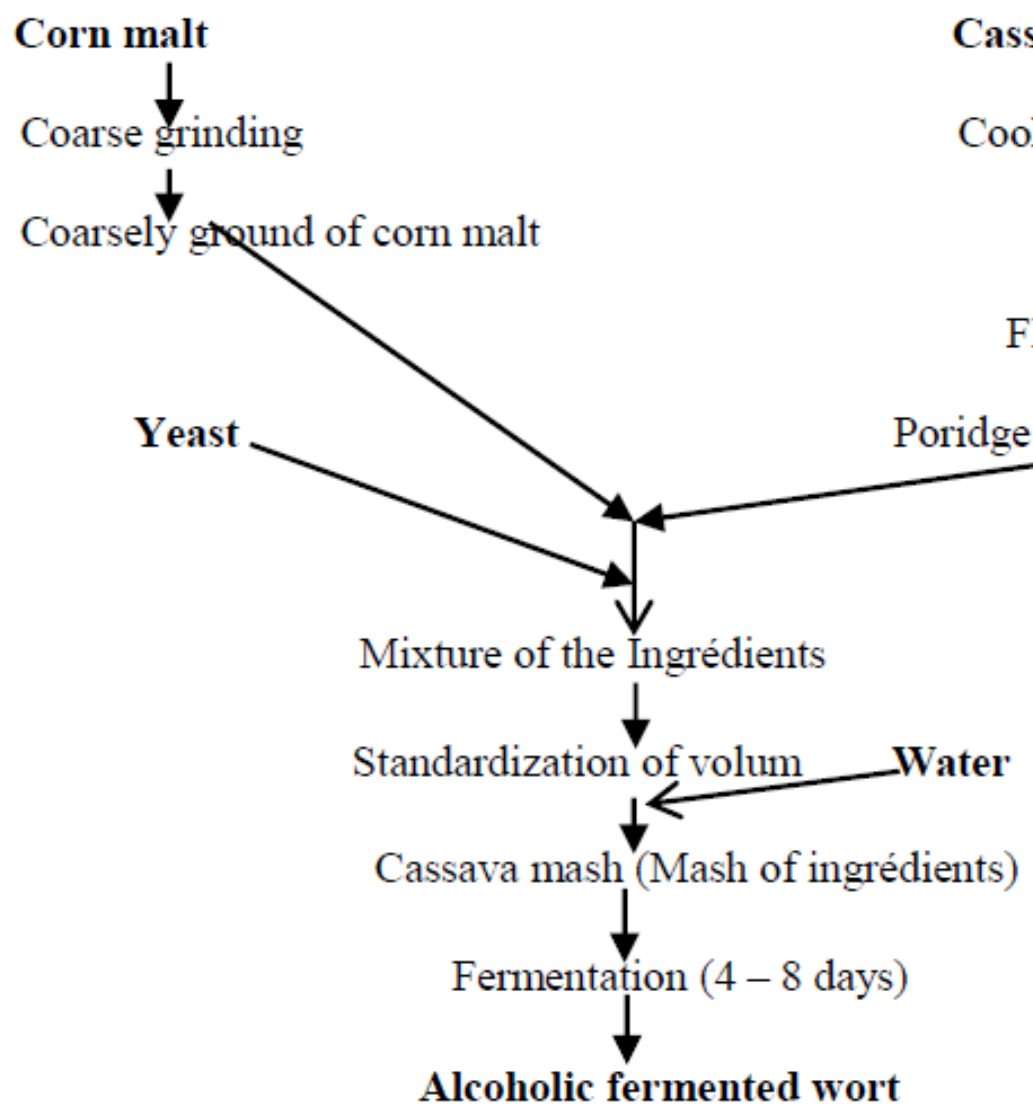


Fig.2 Diagram of distillation process of alcoholic fermented wort and redistillation

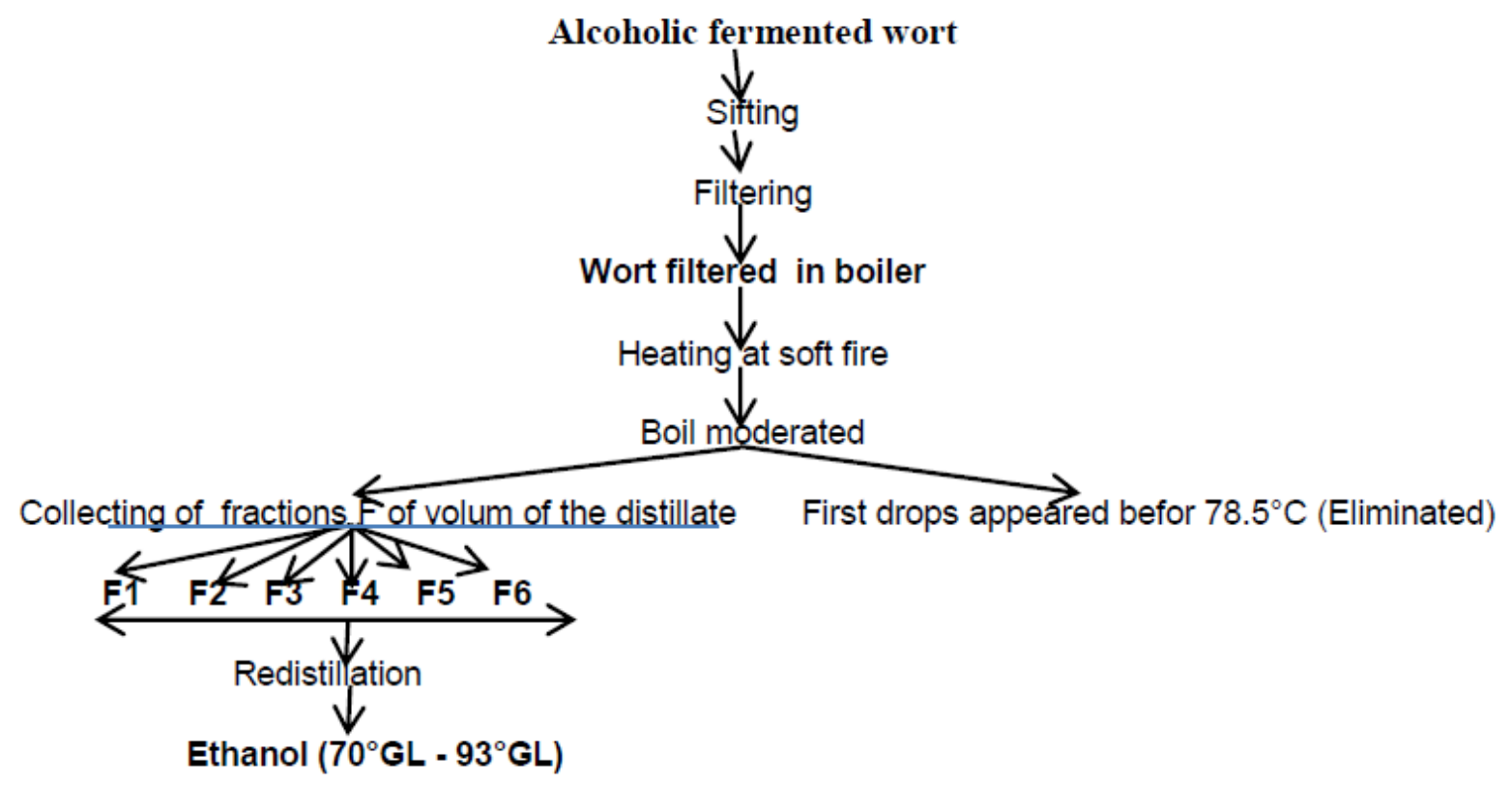

Fig.3 Evolution of the density of cassava mash in terms of adding of corn malt following the ratio $\alpha$-amylase $/$ starch $(\mathrm{U} / \mathrm{g})$. Content of starch tested $=105.5 \mathrm{~g} / \mathrm{L}$.

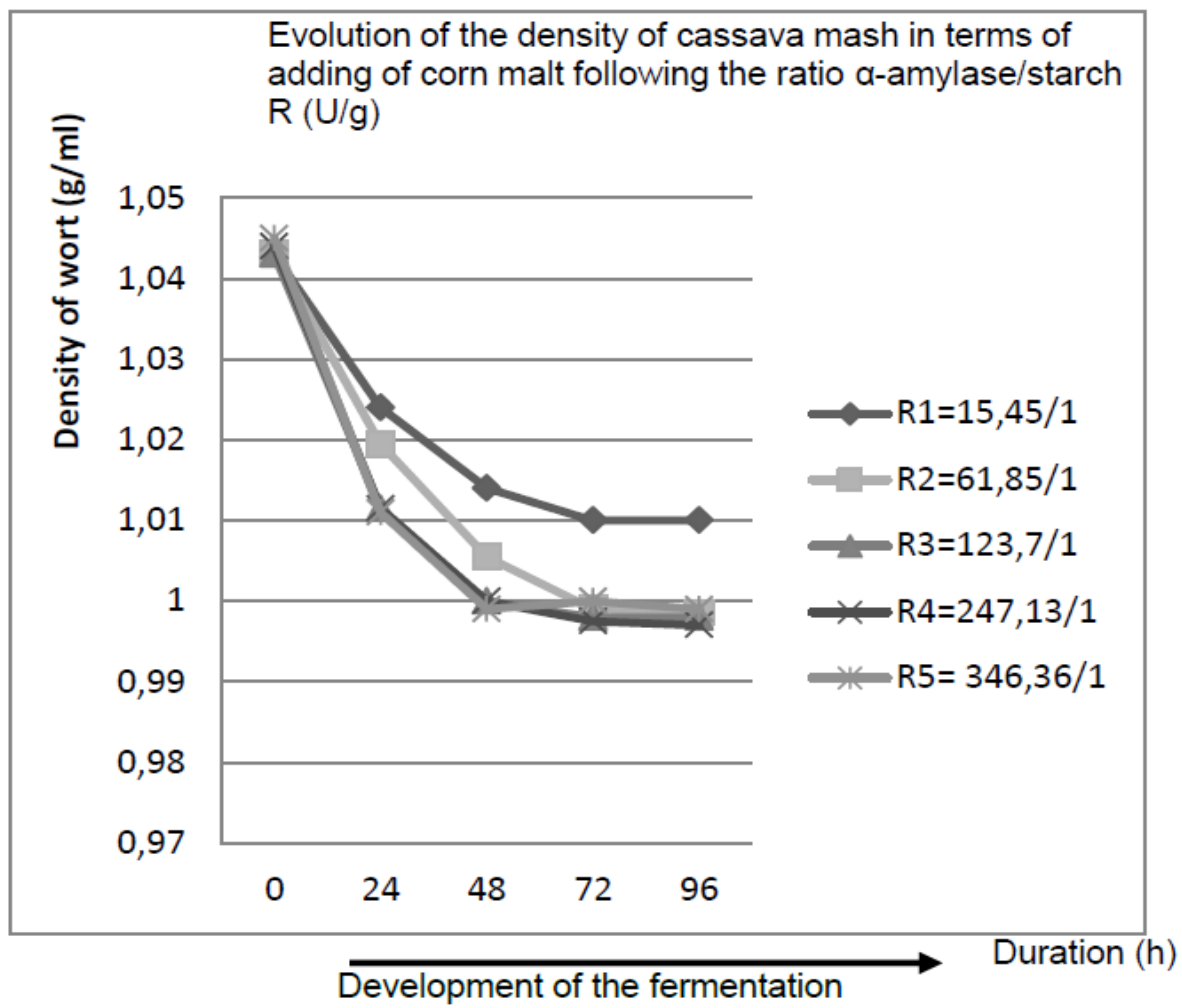

$(\checkmark)$ : Density of the wort with ratio R1=15,45/1, Iodine test $(+)$; $(\boldsymbol{\square})$ : Density of the wort with ratio R2=61,85/1, Iodine test (国);

$(\boldsymbol{\Delta})$ : Density of the wort with ratio R3=123,7/1, Iodine test $(-)$; (X): Density of the wort with ratio R4=247,13/1, Iodine test (-); (*): Density of the wort with ratio R5=346,36/1, Iodine test (-). 
Fig.4 Evolution of the alcoometric title of the fractions of volume of the distillate in terms of corn malt following the ratio $\alpha$-amylase/starch (U/g).

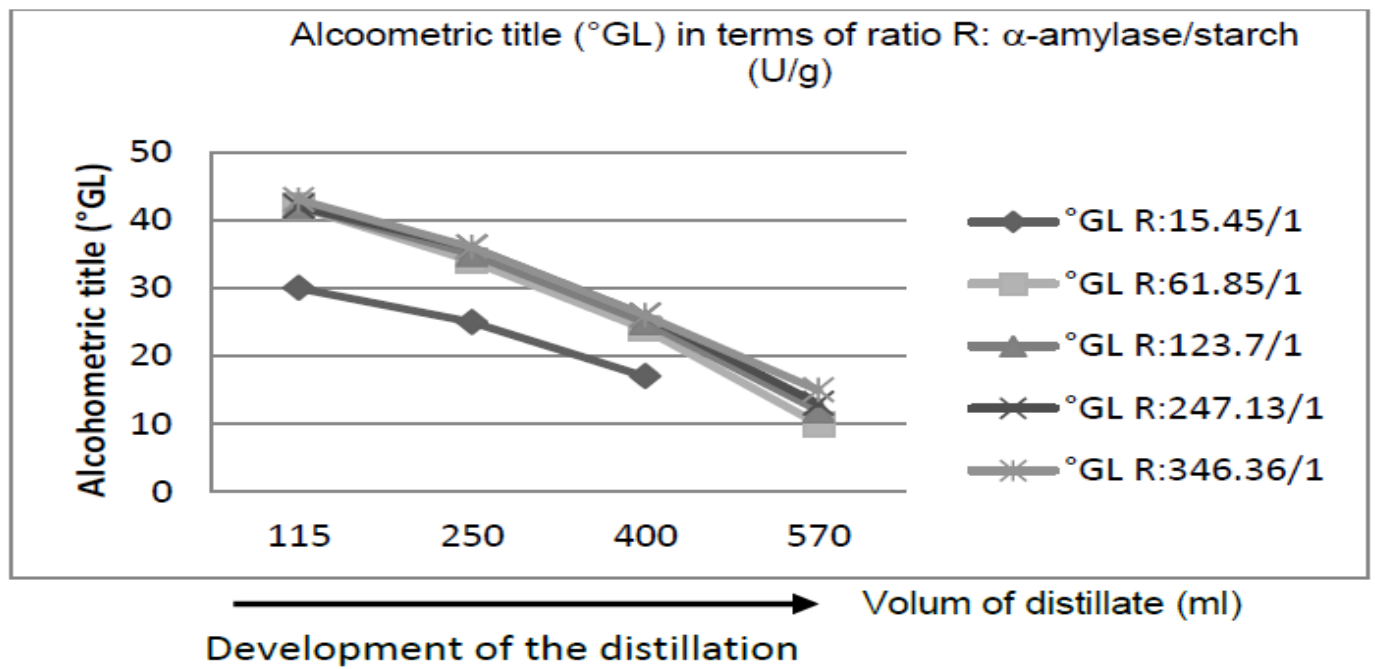

Fig.5 Evolution of the temperature of distillation of alcoholic fermented worts originating of the fermentation with different contents of starch

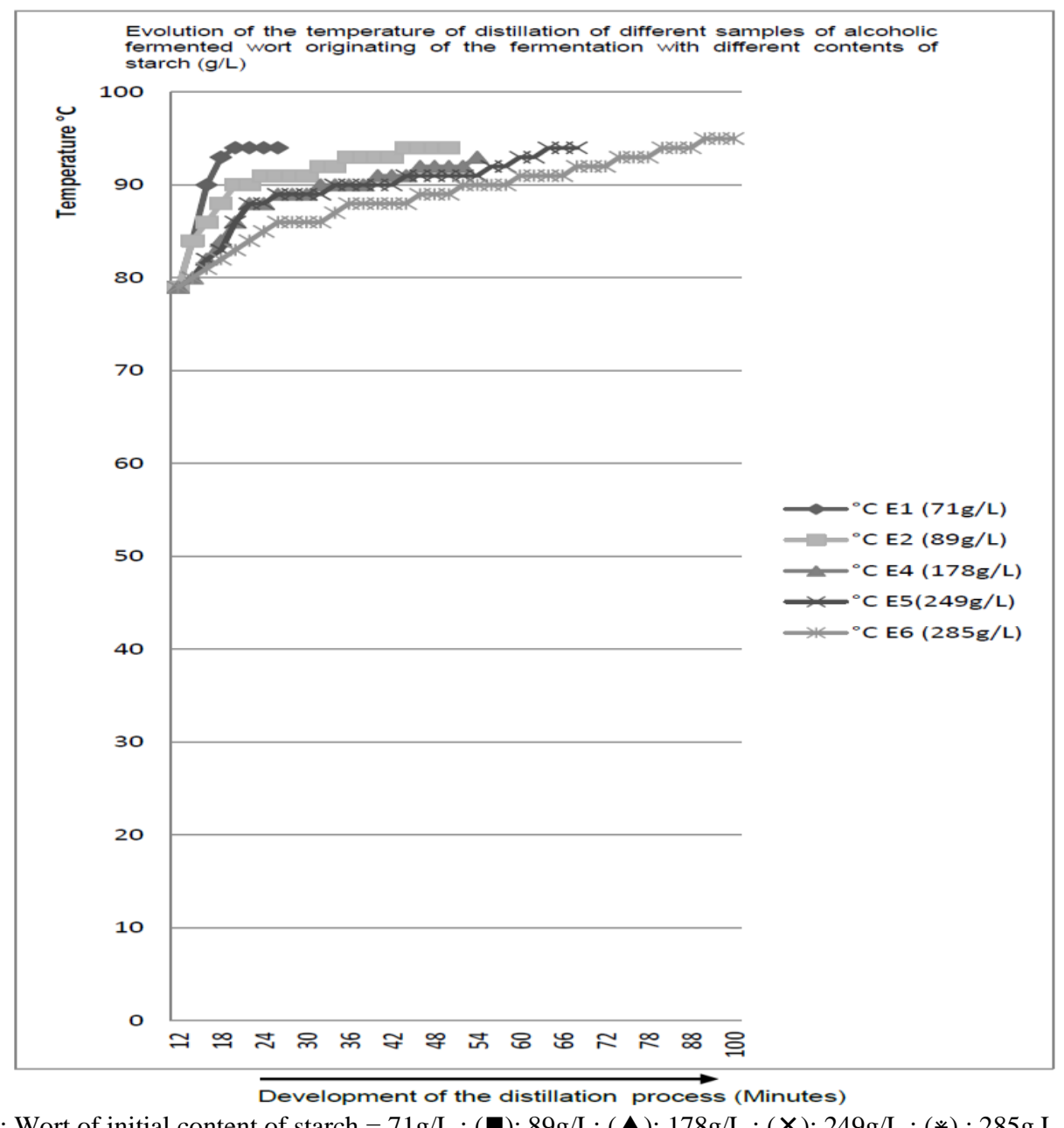

$(\diamond)$ : Wort of initial content of starch $=71 \mathrm{~g} / \mathrm{L} ;(\boldsymbol{\square}): 89 \mathrm{~g} / \mathrm{L} ;(\boldsymbol{\Delta}): 178 \mathrm{~g} / \mathrm{L} ;(\boldsymbol{X}): 249 \mathrm{~g} / \mathrm{L} ;(*): 285 \mathrm{~g} . \mathrm{L}$. 
Fig.6 Evolution of alcoométric titles $\left({ }^{\circ} \mathrm{GL}\right)$ relative at the différent fractions of volume of the distillate in the course of distillation process of alcoholic fermented worts originating of the fermentation process with different contents of $\operatorname{starch}(\mathrm{g} / \mathrm{L})$.

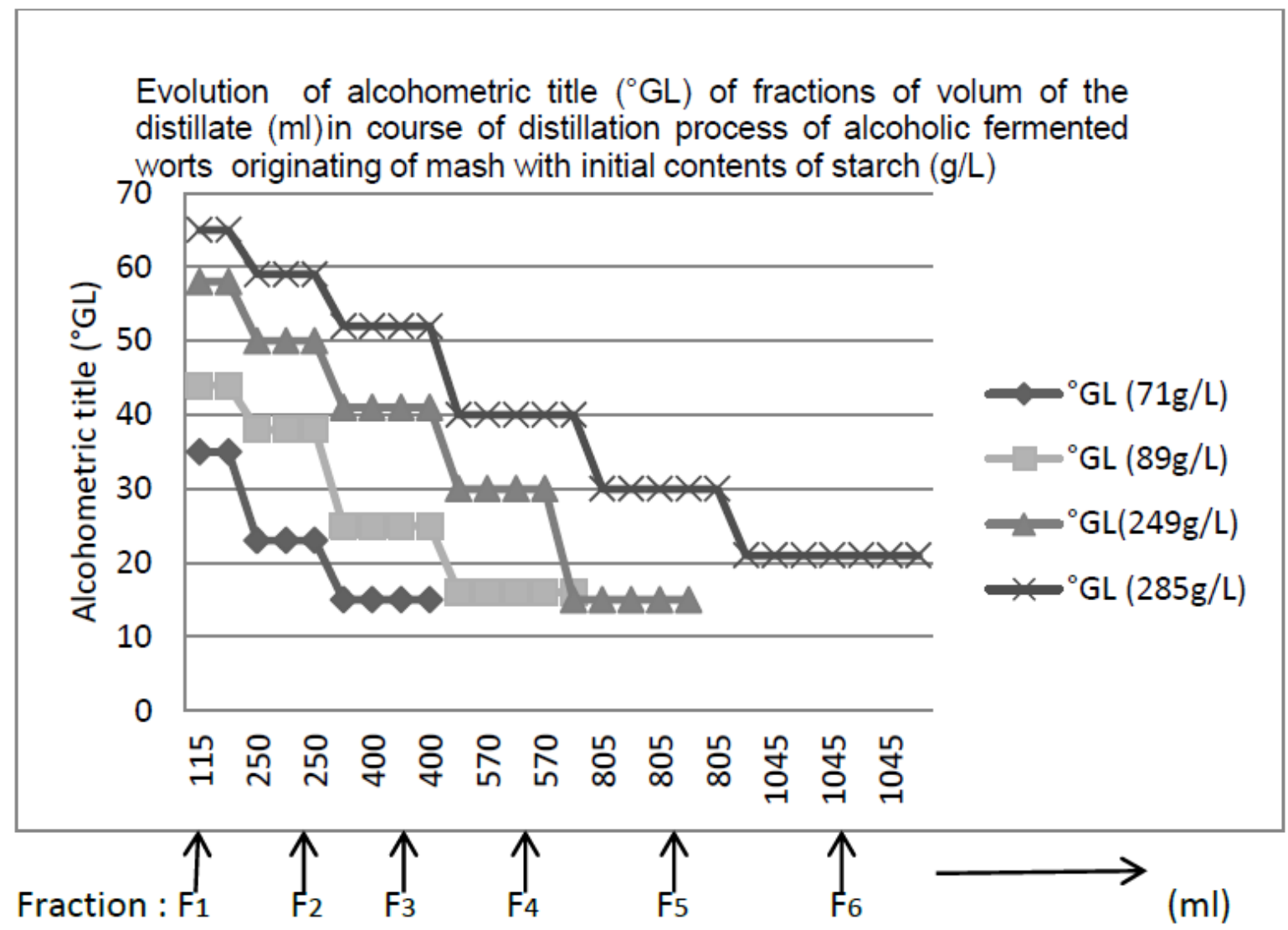

Position of fractions $F$ of volum of the distillate

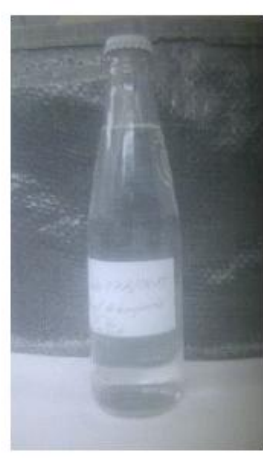

Photo 1. Sample of the first fractions of volum of the distillate $\mathrm{F} 1\left(36^{\circ} \mathrm{GL}\right)$ originating of the mash at $89 \mathrm{~g} / \mathrm{L}$ of starch.

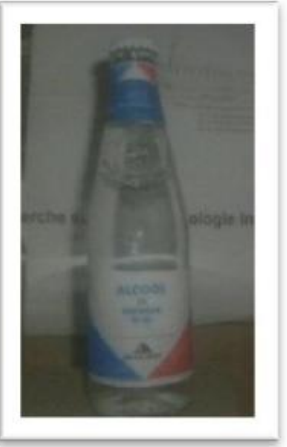

Photo 2. Sample of ethanol concentrated (alcool of boganda at $86^{\circ} \mathrm{GL}$ ) obtained by redistillation of the first fractions of the distillat $\mathrm{F} 1$ originating of the mash at $89 \mathrm{~g} / \mathrm{L}$ of starch. 
The progressive salvage of the different fractions of volume of the distillate, in terms of the dose of alcohol by the operator, is done following the stages of temperature well characterized from $78.5^{\circ} \mathrm{C}-93^{\circ} \mathrm{C}$ to $94^{\circ} \mathrm{C}-96^{\circ} \mathrm{C}$. Every stage of temperature corresponds at a fraction of volume of the distillate having a given dose of ethanol. The doses of ethanol of the fraction of the distillate reaped is as much more important as the density of the fermented wort more high.

The stages of the temperature of distillation process more low correspond at the collecting of the fractions more alcoholic: in the case of fermented wort from the mash at $285 \mathrm{~g} / \mathrm{L}$ of starch, the first fraction doses $65^{\circ} \mathrm{GL}$ and is reaped at $86.82^{\circ} \mathrm{C} \pm 5,3^{\circ} \mathrm{C}$. Thus, there is a relation between alcohometric title of fractions of volume of the distillate and plages of temperature of distillation process of fermented worts originating from a mash at initial content given of starch tested.

The important number of small stages of temperature of distillation reveals a great diversity of pur components and azeotropic mixtures reaped by fractions of distillate (Diakabana et al., 2007). That needs a complementary operation of redistillation of various fractions of volume of the distillate in proceeding from divided distillation with a distillator provided of column of separation in view of best purification and concentrating of the solutions of alcohol obtained.

In conclusion, the cassava mash more dense submit at the ethylic fermentation is best disposed at the distillation process of fermented wort in view to obtain more fractions of the distillate at alcoholic dose elevated and are interesting for the redistillation into bioethanol more concentrated.

The necessary temperature for the distillation process of the ethylic fermented worts denser is more low in comparison with those originating of the worts more light. The reaping of the fractions of the distillate must be done from $78.5^{\circ} \mathrm{C}$. To improve the composition of these ethylic fractions of the distillate, it is necessary to submit the fractions of the distillate obtained at an adequate distillator provided of system of heating permitting a good extraction of ethanol of the different alcoholic fractions.

In view to convert the homescale traditional activity of production of the cassava brandy into industrial process relative at the production of bioethanol more concentrated, one must then obtain regular fractions of volume of the distillate and sufficiently pur so as to put on the market, on the one hand an ethylic fraction destined to medical and chemical domain, on the other an alcohol intended for ironmongery, and as ingredient for preparation of frigoporter fluids (alcoholic water).

\section{References}

Aidoo, K.E. 1994. Application of biotechnology to indigenous fermented foods. Proc. Technol. Dev. Countries; 12: 83-93.

Barcelos, C.A., R.N. Maeda, G.J.V. Btancur and Pereira J.R.N. 2011. Ethanol production from sorghum grains: Evaluation of the enzymatic hydrolisis and the hydrolysate fermentability. Brazil J. Chem. Engi., Vol.28(4) : 597604.

Chlup, Paul, H., Tao Wang Lee and Stewart, G.G. 2007. Assessment of the physiological status of yeast during high-and low-gravity wort fermentations determined by flow 
cytometry. MBAA TQ, vol. 44(4): 286295.

De Vasconcelos, J.N., C.E. Lopes and França F.P. 2004. Continuous ethanol production using yeast immobilised on sugar-cane stalkes. Brazilian J. Chem. Engineer., 21(3), doi:10.1590: S0104663322004000300002.

Diakabana Kiyindou, P. 2008. Possibilités de développement et expansion des bioindustries au Congo. 1ère édition. https://openlibrary.org (Conslté, 3/2013).

Diakabana, P. 2006. Optimization of traditional process of production of boganda, a brandy of Congo. PhD Thesis, Marien NGOUABI University, Brazzaville.

Diakabana, P., 2008a. Optimisation du procédé traditionnel de fermentation dans la production du boganda, une eau-de-vie du Congo. Première partie. ZEBI $\mathrm{N}^{\circ} 001$, Fichetechnique $\mathrm{n}^{\circ} 09$ 08/ANVAR-CG Brazzaville: 51-56.

Diakabana, P., 2008b. Mise au point d'une methode améliorée de distillation du boganda, une eau-de-vie du Congo. Deuxième partie. ZEBI $\mathrm{N}^{\circ} 001$, Fiche technique $\quad n^{\circ} 09-08 / A N V A R-C G$ Brazzaville: 57-61.

Diakabana, P., A. Matondo, A. Ngaka and Ngoma-Makouta Cendrine. 20132014a. Influence du mode de trempage du grain de maiis sur le déroulement du processus traditionnel du maltage de maiis dans la production du boganda, une eau-de-vie du Congo. Annales de l'Université Marien NGOUABI, 1314(4): 1-12.

Diakabana, P., C.A.G. Nyanga-Koumou, S.C. Kobawila, D. Louembé and Derdelinckx G. 2008. Study of characteristic parameters of traditional process in the production of boganda, a brandy of Congo. Int. J. Biol. Chem. Sci., 2(3): 258-271.

Diakabana, P., D. Louembé and Kobawila S.C. 2007. Biochemical and physicochemical characteristics of the fermentation of Boganda, a brandy of Congo. Res. J. Biotechnol., 2(1): 1825.

Diakabana, P., M. Mvoula-Tsiéri, J. Dhellot, S.C. Kobawila and Louembé D. 2013b. Physico-chemical characterization of falling on the brew brewing malt corn in the production of maize beer in Congo. Adv. J. Food Sci. Technol., 5(6): 671-677.

Diakabana, P., R.F. Niama, A.C. Mvila, I. Louzolo, S.C. Kobawila, Louembe, D. 2014b. Behavior of fermentable sugars in the traditional production process of cassava bioethanol. Adv. J. Food Sci. Technol., 6(10): 1104-1111.

Diakabana, P., S. Dinga Boudjoumba, A.C. Mvila, S.C. Kobawila and Louembé D. 2014c. Isolation and screening of yeast strains involved in performing of traditional production process of cassava bioethanol. Int. J. Curr. Microbiol. App. Sci., 3(6): 671-684.

Diakabana, P., S.C. Kobawila, Vivianne Massengo and Louembé, D. 2013a. Effet du degree de maturation sur la cinétique de fermentation éthylique de la pulpe de mangue cultivar Boko. Cameroon J. Experimental Biol., 9(1): 1-8.

Ganesan Sasikala and Nellaiappan Olaganathan Gopal. 2014. Exploration of wild yeast strains for thermotolerance and ethanol production. Res. J. Chem. Environ., 18(1) : 14-22.

Gauthier, M., R. Tremblay and Deslauriers M. 2005. Contrôle du procédé de fermentation alcoolique. Institut de Technologie Agroalimentaire, Québec.

Gosselin, Y., A. Debourg and Fels, S. 2000. Industrial use of dry yeast in brewing. Bios, No. 2, Congress: 32-38.

Holzapel, W. 1997. Use of cultures in fermentation on a household scale. Food Control. Elsevier Science Ltd. Vol. 8. N5/6 : 241-258.

Johannes Tippman, Jens Voigt and Karl Sommer. 2008. Correlation between 
fineness of malt grist and particle size and conversion during the mashing and filtration process, $M B A A T Q$ vol. $45(1)$ : 8-12.

Launder Kelly. 2001. From promise to purpose: Opportunities and constraints for ethanol-based transportation fuels. Master of Science, Michigan State University: 49pp.

Manuel Fernando Rubio-Arroyo, Pilar Vivanco-Loyo, Moisés Juarez, Matha Poisot and Guillermo Ramirez-Galicia. 2011. Bio-ethanol obtained by fermentation process with continuous feeding of yeast. J. Mex. Chem. Soc., 55(4): 242-245.

Moreau, C. 1985. L'industrie japonaise et les biotechnologies: le consensus et la compétition. Cahiers des Ingénieurs Agronomes INA-PG; Mensuel N ${ }^{\circ} 382$.

Muyanja C., S. Birungi, M. Ahimbisibwe, J., Semanda and Namugumya, B.S. 2010. Traditional processing, microbial and physicochemical changes during fermentation of malwa. African J. Food Agri. Nutri. Develop., Vol. 10 (10) : 4124-4138.

Rakotosaona, R., T. Andrianonintsoa, R. Ratokosaona, O. Andrianaivoravelona, E. Andrianarison, J.D. Ramaroson and Andrianary P. 20015. Mise au point d'un procédé de fabrication d'une boisson alcoolisée à base de manioc. MADA-HARY Vol.3.

Seinosuke Ueda, Celia, T., Zenin, Domingos, A. Monteiro, Yong, K. Park. 1981. Production of bioethanol from raw cassava starch by a nonconventional fermentation method. View issue TOC Vol.3, issue 2 : 291-299. DOI : 10.1002/bit.260230205 (Consulté, le19/8/2016).

Stewart, G.G., Takeshi Yonesawwa and Martin S.A. 2008. Influence of mashing conditions on fermententation characteristics of all-malt wort used to produce beer or whisky. MBAA $T Q$, vol.44(4): 256-263.

Take Ajaykumar, M. and Kharat Rajhans, G. 2012. Production and characterization of $\alpha$-amylase isolated from Aspergillus Niger by soil state fermentation. Res. J. Biotech., 7(4): 36-45.

Tiisekwa, A.B., T.C.E. Mosha, H.S. Laswai and Towo, E.E. 2000. Traditional alcoholic beverages of Tanzania: production, quality and changes in quality attributes during storage. Int. J. Food Sci. Nutr., 51: 135-143.

Van Noort, G., Spence, C. 1976. The Mahewu industry. S. Afr. Food Rev., 10: 129133.

World Bank. 1980. Alcohol production from biomass in the developing countries. 1818 H Street, N.W., Washington, D.C. 20433, USA.

Zannou-Tchoko, V.J., L.B. Ahui-Bitty, Kofi Kouamé, G.M. Bouaffou and Dally T. 2011. Utilisation de la farine de maïs germé source d'alpha amylases pour augmenter la densité énergétique de bouillies de sevrage à base de manioc et son dérivé, l'attiéké. J. Appl. Biosci., 37: 2477-2484.

\section{How to cite this article:}

Diakabana Philippe, Simon Charles Kobawila and Delphin Louembé. 2016. Correlation between Initial Content of Starch of the Mash of Cassava (Manihot esculenta L) in Fermentation and Temperature of Distillation of Alcoholic Fermented Wort in the Course of the Production of Bioethanol in Congo. Int.J.Curr.Microbiol.App.Sci. 5(10): 997-1009. doi: http://dx.doi.org/10.20546/ijcmas.2016.510.106 